\title{
Bertrand and Cournot competition under asymmetric costs: number of active firms in equilibrium
}

\author{
Andrew Ledvina* $\quad$ Ronnie Sircar ${ }^{\dagger}$
}

First draft October 2010; current version 18 February 2011

\begin{abstract}
We compare the number of active firms, i.e. the number of firms producing a positive quantity, in equilibrium across four different models of oligopoly: Cournot and Bertrand with homogeneous or differentiated goods. We concentrate on the linear demand structure with constant marginal but asymmetric costs. (With symmetric costs, the results trivialize to all firms active or all firms inactive.) When firms have different costs, we show that, for fixed good type, Cournot always results in more active firms than Bertrand. Moreover, with a fixed market type, differentiated goods result in more active firms than homogeneous goods. Hence, consumers pay for more choice in a Cournot market relative to Bertrand.
\end{abstract}

JEL classification: C72; D43; L11; L22

Keywords: Oligopolies; Bertrand model; Cournot model; Differentiated goods.

*ORFE Department, Princeton University, Sherrerd Hall, Princeton NJ 08544; aledvina@princeton.edu. Work partially supported by NSF grant DMS-0739195.

†ORFE Department, Princeton University, Sherrerd Hall, Princeton NJ 08544; sircar@princeton.edu. Work partially supported by NSF grant DMS-0807440. 


\section{Introduction}

The main focus of this paper is to study the number of firms in an oligopoly who actively produce in equilibrium when they have different costs of production. Asymmetric costs are commonplace in markets of large and small producers (for example Barnes \& Noble vs. an independent local bookstore), where the larger firm can achieve economies of scale. However, most analyses assume symmetric costs, or restricted cost structures that guarantee all firms are active in equilibrium. Whether a firm produces a positive quantity in an equilibrium is an important question in the study of oligopolistic competition because it can be used to explain market variety as a cost to the consumer.

We focus on both the Cournot and Bertrand static games, which allows for a clean interpretation of the results, and our analysis is complementary to the existing literature on entry/exit decisions of firms. Within each of these models, we have two cases: when the goods are homogeneous, and when they are differentiated. We will show that, within a fixed type of market, Cournot or Bertrand, differentiated goods result in more active firms in equilibrium than homogeneous goods. These results depend crucially on cost asymmetries between the firms, as with symmetric costs the results trivialize to all firms active or all firms inactive. Our results, e.g. Theorem 4.1, partially explain the relative differences to consumers between these two types of markets, as consumers have more choice in Cournot markets but with higher prices, whereas they have less choice in Bertrand markets (as the number of firms in equilibrium is less) but they are compensated for this fact by reduced prices.

\section{$1.1 \quad$ Background}

The study of non-cooperative oligopolistic competition originated with the seminal work of Cournot [7]. His original model assumed firms choose quantities of a homogeneous good to supply and then receive profit based on the single market price as determined through a linear inverse demand function of the aggregate market supply. Moreover, marginal costs of production were assumed constant and equal across firms. Throughout this paper, we also assume constant marginal costs, however we drop the cost symmetry assumption. The result of Cournot's analysis is what one would expect: with equal marginal costs across firms, every firm chooses the same quantity to supply and the market price is above cost by an amount that is inversely proportional to one plus the number of firms in the market. Hence, as the number of firms tends to infinity, the price approaches marginal cost, but with a finite number of firms, prices are above cost and firms earn positive profits.

Following this, Bertrand [4] argued to change the strategic variable from quantity to price. Firms producing a homogeneous good were assumed to set prices and produce to meet any demand of the market. As the goods are homogeneous, there can only be one market price, as observed in the Cournot model above, and therefore only the firm quoting the minimum price receives any demand. This feature of one price leads to very harsh and contradictory results relative to common market observations. If all firms have equal cost, then as long as there are two or more firms in the market, all firms price at cost and have zero profit. This perfectly competitive outcome differs substantially from the Cournot outcome and is commonly referred to as the Bertrand paradox. To paraphrase from [24], the Bertrand model results in perfect competition in all cases besides monopoly, which is unrealistic in most settings, leading one to conclude that the correct set-up 
leads to the wrong result. On the other hand, as most firms seem to set their prices, not their quantities, many economists have argued that the Cournot model gives the right answer for the wrong reason.

Since these two original papers, there has been much interest in modifying these models in various ways to obtain more realistic results. Furthermore, there is a significant literature comparing the two modes of competition when some of the assumptions in the original papers are altered. These modifications are usually brought about to reconcile the Bertrand paradox. If one considers constraints on the capacity of the firms, see Edgeworth [10], then the result of the Bertrand model can be brought closer to that of the Cournot model. Kreps and Scheinkman [21] use capacity constraints to obtain the Cournot outcome from Bertrand competition. As such, the Bertrand model cannot really be thought of as complete without more realistic assumptions.

One of the original assumptions that is commonly not satisfied is the assumption that goods are homogeneous. This leads one to consider differentiated goods, which can mean either substitute or complementary goods, although we concentrate on the case of substitute goods. The original work in this area is Hotelling [18], where consumers were assumed to associate a cost of travel depending on the location of the firms, thereby differentiating their otherwise identical goods based on the location of the firms relative to the location of the consumer. For classical results on differentiated goods and other models of oligopoly, we refer to the books by Friedman [12] and Vives [29].

\section{$1.2 \quad$ Asymmetric Costs}

Very often, modifications of the original models are made under the assumption of symmetric marginal costs across firms. This assumption allows one to simplify the analysis considerably and, in particular, one does not have to consider the case of some of the firms being costed out of the market. That is, either all firms are active in that they receive positive demand, or none of the firms are. When one considers an asymmetric cost structure, the issue of the number of firms who are active in an equilibrium becomes crucially important. This fact is often overlooked or assumed away in studies of asymmetric cost, see for example [20] and [1]. As we will see though, it is not always the case that inactive firms can simply be ignored - their presence may affect equilibrium quantities and prices.

This is not to say that the number of firms active in a market has not been studied before. The issue is generally studied in terms of entry and exit from a market in a dynamic setting, see for example [11] and [3]. Although this is an interesting perspective from which to analyze this question, it is not one we deal with here, but some of these issues are discussed in [16] and [23]. Additionally, the problem has been studied in terms of establishing the existence of equilibria and the welfare properties of the various possible equilibria, see for example [2] and references therein. This issue does not arise in our setting as we explicitly construct an unique equilibrium for each case we study. We refer also to $[6 ; 25]$ for an analysis of consumer surplus under Bertrand and Cournot modes of competition, but again with symmetric (and zero) costs.

The issue of asymmetric cost in oligopolies has been addressed before. In the work of Singh and Vives [26], they consider a game in which firms in a differentiated duopoly can choose to offer either price or quantity contracts to consumers. Essentially this allows firms to select either Bertrand or Cournot competition. They show for substitute goods that it is always a dominant strategy for 
both firms to choose the quantity competition. The majority of their analysis is in the case of linear demand although they discuss nonlinear demand as well. However, they derive their results under the assumption that both firms are active in equilibrium. In a related work, Zanchettin [30] compares prices and outputs in a duopoly with linear demand where the firms can have asymmetric costs and the goods are differentiated. The main idea is to remove the assumption that both firms are active in equilibrium and to consider the effect of this on prices and outputs. The main results of this paper are that prices are lower in Bertrand compared to Cournot, however outputs of both firms may not always be greater in the Bertrand market relative to the Cournot market. Furthermore, industry profits can be higher in Bertrand than in Cournot for certain parameter values. This work is closest to ours although as it is a duopoly model, the possible number of active firms is restricted to one or two which simplifies the analysis considerably. Furthermore, additional asymmetries are tractable in a duopoly that are essentially unworkable in an $N$-firm oligopoly

The comparison of Cournot and Bertrand oligopoly models has produced a vast literature, and we refer to [1] and references therein. Additionally, the results are in no way clear-cut as they tend to be highly dependent on modeling assumptions. For example, Singh and Vives [26] find that Bertrand competition is always better for consumers if goods are substitutes. Then, Hackner [15] finds that this is not always true in oligopolies with the opposite being possible in certain situations, as the former result depends crucially on the duopoly setting. Hsu and Wang [19] find that consumer surplus and total surplus are in fact higher under Bertrand competition relative to Cournot competition regardless of whether goods are substitutes or complements. However, modifying the assumptions, Symeonidis [27] introduces research and development to the model and finds that this can lead to situations where Cournot competition is more beneficial than Bertrand competition both for consumers and for firms in terms of output, consumer surplus and total welfare.

Cournot and Bertrand competitions can be seen as extremes of different oligopoly types, with the mode of competition dictated more by the type of good than by any choice made by firms. For example, the consumer market for televisions cannot reasonably be modeled by a Cournot oligopoly because firms actually set prices not quantities. In some settings, firms make production quantity decisions and price decisions more or less simultaneously, and therefore a mixture of the two modes of competition is more realistic. d'Aspremont et al. [8] parameterizes this concept as competitive toughness and allows for competition across the Bertrand-Cournot spectrum. This is one manner in which to merge the two concepts.

Static Cournot/Bertrand games also arise as an intermediary in their dynamic counterparts, where asymmetric shadow costs encode firms' scarcity values as their resources or capacities deplete. See [16] for a Cournot dynamic game with exhaustible resources and [23] for a dynamic Bertrand game in which firms of different sizes begin competing with asymmetric lifetime capacities. Study of these leads to the issue of blockading - where some firms may be inactive due to high shadow costs until the resources of their competitors fall (and their shadow costs rise) accordingly. Hence, a thorough analysis of the activity levels in the static Cournot and Bertrand games is needed, which is the purpose here.

In the following sections, we analyze the number of firms who are active in equilibrium in Cournot type and Bertrand type oligopolies in the case of both homogeneous and differentiated goods when the firms have asymmetric costs. We carry out our analysis in the specific case of linear demand, to assess explicitly what factors are necessary to determine the active number of firms in a given market. Our results can be used to partially assess the merits of the commonly held view that a 
Bertrand equilibrium is more competitive than the corresponding Cournot equilibrium.

\section{Models of Oligopolistic Competition}

We start with a competitive market that has $N \geq 1$ firms. Let $q_{i}$ be the quantity produced by Firm $i$, and similarly let $p_{i}$ be the price charged for their respective good. Dropping the subscript, we denote by $p$ and $q$ the vector of all prices or quantities, respectively. Let $Q_{-i}=\left(q_{1}, \ldots, q_{i-1}, q_{i+1}, \ldots, q_{N}\right)$ and $P_{-i}=\left(p_{1}, \ldots, p_{i-1}, p_{i+1}, \ldots, p_{N}\right)$. These are the vectors of quantities and prices of all the firms except Firm $i$. Moreover, we define $Q=\sum q_{i}$ and $P=\sum p_{i}$ as the aggregate quantity and price, respectively.

\subsection{Substitutability of Goods}

We focus on two types of markets: those where the goods being sold are similar but different, and those where the goods are identical.

Differentiated goods means that the goods are not perfect substitutes for one another. Each firm can in principle then receive demand even if they are not the lowest price firm or the firm producing the highest quantity. This does not mean they will receive demand, it only means that consumers have preferences beyond price and/or quantity that results in the purchase of goods at a seemingly less favorable price because of other factors. There are $N$ possible price-quantity pairs and each firm has its own inverse or direct demand function depending on the mode of competition. However, across these functions, firms are distinguished only by the price or quantity they set. For example, two firms with equal price will receive equal demands.

Homogeneous goods means that the goods sold by the different firms are perfect substitutes for one another. Therefore, only one price can prevail in the market. In the case of firms choosing quantities, this does not add undue burden at all, as it simply implies that the price a firm receives will depend on the aggregate market supply and their profit will then depend on that price and their chosen quantity. The case of firms setting prices is more complicated. Each firm can offer a price, but only one price can ultimately prevail in the market as goods are deemed identical. Thus, only the firms setting the lowest price will receive demand from the market. The rest can post a price, but as they will not receive demand at this higher price, it is irrelevant. The only issue that arises is in a tie for the lowest price. To accommodate this important case, one must define precisely how the lowest price firms share demand in equilibrium. These rules are commonly referred to as sharing rules and can have important equilibrium consequences, see for example [17]. We shall be explicit in what follows which sharing rule we use and our reason for doing so.

\section{$2.2 \quad$ Linear Oligopolies}

We concentrate on a linear demand specification in order to present explicit calculations, particularly for the number of active firms in equilibrium. However, the existence of an equilibrium in each of the four models can be established in more general settings: for the homogeneous Cournot case, see [16, Section 2], and [23, Section 2] for the differentiated Bertrand case. 
We derive demand from the behavior of a representative consumer with the following quadratic utility function:

$$
U(q)=\alpha \sum_{i=1}^{N} q_{i}-\frac{1}{2}\left(\beta \sum_{i=1}^{N} q_{i}^{2}+\gamma \sum_{\substack{i=1 \\ j \neq i}}^{N} \sum_{\substack{j=1 \\ j \neq i}}^{N} q_{i} q_{j}\right), \quad \alpha, \beta>0 .
$$

Our representative consumer solves the utility maximization problem

$$
\max _{q \in \mathbb{R}_{+}^{N}} U(q)-\sum_{i=1}^{N} p_{i} q_{i},
$$

from which we can derive the inverse demand functions for the firms as

$$
p_{i}(q)=\frac{\partial U}{\partial q_{i}}=\alpha-\beta q_{i}-\gamma \sum_{j \neq i} q_{j}, \quad i=1, \cdots, N
$$

This gives actual quantities provided $p_{i}>0$ for all $i$. In the case that the quantities result in any of the prices not being positive, we must remove the individual firm with the highest quantity from the system and then consider a market with one less firm. If any of the prices are still not positive, then we repeat this procedure, one firm at a time, until we have a market with positive prices for all firms.

The parameter $\gamma$ can be positive, negative or zero depending on whether the goods are substitutes, complements or independent.

Definition 2.1. Within the linear set-up, the following concepts can be characterized:

- Independent goods $\quad \gamma=0$;

- Substitute goods $\quad \gamma>0$;

- Differentiated goods $\quad \gamma<\beta$;

- Homogeneous goods $\quad \gamma=\beta$.

We will not deal with the case of complementary goods which corresponds to $\gamma<0$. The quantity $\gamma / \beta$ expresses the degree of product differentiation, which ranges from zero (independent goods) to one (perfect substitutes, or homogeneous goods).

When $\gamma<\beta$, the system (3) can be inverted to obtain

$$
q_{i}(p)=a_{N}-b_{N} p_{i}+c_{N} \sum_{j \neq i} p_{j}, \quad i=1, \cdots, N,
$$

where for $1 \leq n \leq N$, we define

$$
\begin{aligned}
a_{n} & =\frac{\alpha}{\beta+(n-1) \gamma}, \\
b_{n} & =\frac{\beta+(n-2) \gamma}{(\beta+(n-1) \gamma)(\beta-\gamma)} \\
c_{n} & =\frac{\gamma}{(\beta+(n-1) \gamma)(\beta-\gamma)}
\end{aligned}
$$


As in the case of inverse demands, (4) gives the actual quantities if they are all strictly positive. If some of them are not positive, then we consider the case where the firms are ordered by price such that $p_{1} \leq p_{2} \leq \cdots \leq p_{N}$. Then, we remove the price and quantity of firm $N$ from the utility function and repeat the above procedure. If some remain that are not positive, we continue removing firms in this manner one at a time until we have only firms with positive quantities remaining. The equivalent manner to remove them at the level of the demand functions is to again consider the firms ordered by price, and to remove the price and quantity of Firm $N$ from the system and use (5)-(7) with $n$ equal to $N-1$. If firms still remain with negative quantity in this reduced demand system, then we again continue this procedure one firm at a time until only firms with positive quantity remain. If firms are not ordered by price, we can re-label them for this procedure and then restore their correct labels once the demand system is determined. For differentiated goods, (3) gives the inverse demand functions relevant to the Cournot market, and (4) gives the demand functions relevant to the Bertrand market.

For homogeneous goods, we need to consider the limit of the utility function in (1) when $\gamma=\beta$. This is no problem for the inverse demand functions and we arrive at

$$
p_{i}^{H}(q)=\alpha-\beta \sum_{j=1}^{N} q_{j}, \quad i=1, \cdots, N,
$$

where the $H$ stands for Homogeneous, which is to differentiate this inverse demand function from that in (3). This is the same price for all of the firms and it depends only on the aggregate supply in the market. The difficulty with the Bertrand market is that we cannot invert this relationship.

The issue that arises in the Bertrand case can best be presented with a two-firm duopoly example. If we suppose $p_{1}$ is fixed and $p_{2}=p_{1}+\epsilon$ then $q_{2}(p)=a_{2}-\left(b_{2}-c_{2}\right) p_{1}-b_{2} \epsilon$, and $q_{1}=a_{2}-\left(b_{2}-c_{2}\right) p_{1}+c_{2} \epsilon$. As $\gamma$ approaches $\beta$, we have $\left(b_{2}-c_{2}\right) \rightarrow \infty$. Thus, for $\gamma$ sufficiently close to $\beta$ we will have $q_{2}<0$. However, when this occurs, the demand function for Firm 1 changes in a consistent manner to reflect the fact that Firm 2 is out of the market. This is accomplished by using (5)-(7) with $n=1$. If $p_{1}=p_{2}=p$, then we have from (8) that $\left(q_{1}+q_{2}\right)=\frac{\alpha}{\beta}-\frac{1}{\beta} p$. In other words, the quantities of the two firms must add up to the quantity that a single firm would receive if they set the lowest price alone. Furthermore, as firms are distinguishable only by the prices they set, equal prices must imply they get equal demand. Moreover, as we have established what the sum of their demands is, we know that each gets an equal share of this demand. In this way we obtain

$$
q_{i}^{H}(p)=\frac{\left(\frac{\alpha}{\beta}-\frac{1}{\beta} p_{i}\right)}{\#\left\{k: p_{k} \leq p_{j} \forall j\right\}} \mathbb{1}_{\left\{p_{i}=\min (p)\right\}} \cdot
$$

For an $N$-firm oligopoly, the procedure for determining demand is identical as that above, where firms are removed from the demand system one-by-one as their quantities go negative. We thus arrive at the same conclusion regardless of the number of firms. This is the classical "winner-takeall" Bertrand model with monopoly demand $\frac{\alpha}{\beta}-\frac{1}{\beta} p$.

\section{Nash Equilibria of the Four Game Types}

We assume that each firm has constant marginal cost, which we denote by $s_{i}$ for Firm $i$. We denote by $s$ the vector of such costs. Our main goal is to demonstrate how cost asymmetries, coupled with the degree of product differentiation and the mode of competition, affect the structure of a market. 
Each firm chooses its price or quantity to maximize profit in a non-cooperative manner, although they do so taking into account the actions of all other firms. Therefore, we assume firms make decisions to maximize profit in the sense of Nash equilibrium. The argument of the profit function that each firm maximizes over depends on the mode of competition, but in all cases the profit function is given by

$$
\Pi_{i}=q_{i} \cdot\left(p_{i}-s_{i}\right) .
$$

Remark 3.1. It is straightforward to see that if we started with firms having individual $\alpha_{i}$ in (1), then this can be reduced to the identical $\alpha$ case by absorbing the different $\alpha_{i}$ into the costs $s_{i}$ in (10). However, we do not treat the case of individual $\beta$ 's or $\gamma$ 's here.

We suppose that the $N$ firms are ordered by cost such that $0<s_{1} \leq s_{2} \leq \cdots \leq s_{N}$. This is for expositional simplicity; one can simply relabel the firms to compute equilibria and then return the original labels to the firms. Further, we assume that $s_{N}<\alpha$, which rules out the possibility of a firm never wishing to participate in an equilibrium. The next four subsections give the Nash equilibria for the Cournot and Bertrand games for markets with differentiated and homogeneous goods.

\subsection{Differentiated Cournot Competition}

Throughout this section, we roughly follow [16] wherein the results of the homogeneous Cournot game with general price functions is given. Although here we are dealing with the differentiated Cournot model, the method for constructing the Nash equilibrium is very similar for the case of linear inverse demands. We shall present here the full details of the construction in the differentiated goods setting.

The profit function of the firms is given in (10), and here the firms maximize over $q_{i}$ with price given as the function of $q$ in (3). If all the equilibrium quantities are strictly positive, then the first-order conditions give the best-response function for a given firm:

$$
q_{i}^{B R}=\frac{1}{2 \beta}\left(\alpha-\gamma \sum_{j \neq i} q_{j}-s_{i}\right), \quad i=1, \ldots, N .
$$

We can sum these equations over $i$ to obtain

$$
0=-2 \beta Q+N \alpha-\gamma(N-1) Q-S^{(N)},
$$

where we let $S^{(n)}=\sum_{j=1}^{n} s_{j}$, the sum of the costs of the first $n$ firms. We define the candidate equilibrium total production $Q^{\star, N}$, as the solution to the scalar equation $f_{N}(Q)=S^{(N)}$, where

$$
f_{N}(Q)=N \alpha-(2 \beta+(N-1) \gamma) Q, \quad Q>0 .
$$

Let us define the following effective market price function: $\bar{P}(Q)=\alpha-\gamma Q$. This is not an actual price in the market, but it is a useful mathematical tool. We use the description effective as we shall see that this price serves the purpose of the single price in the market that all costs must be compared to. With this market price function, we can rearrange (11) to obtain a candidate Nash equilibrium

$$
q_{i}^{\star, N}=\frac{\bar{P}\left(Q^{\star, N}\right)-s_{i}}{2 \beta-\gamma}, \quad i=1, \ldots, N
$$


Utilizing (12) and (14), we can express the candidate equilibrium as

$$
q_{i}^{\star, N}=\left(\frac{\bar{P}\left(Q^{\star, N}\right)-s_{i}}{\sum_{j=1}^{N}\left(\bar{P}\left(Q^{\star, N}\right)-s_{j}\right)}\right) Q^{\star, N} .
$$

The expression in (15) is convenient for expressing the candidate equilibrium quantities as it has the interpretation that once total equilibrium quantity $Q^{\star, N}$ is determined, each player produces the fraction which is the deviation of his cost $s_{i}$ from the effective market price $\bar{P}\left(Q^{\star, N}\right)$ relative to the total deviation of all players' costs from that price.

However, it may occur that $q_{i}^{\star, N}<0$ for some $i$, which is not an admissible solution and we must thus consider equilibria with less than $N$ firms. For $1 \leq n \leq N$, we define

$$
f_{n}(Q)=n \alpha-(2 \beta+(n-1) \gamma) Q, \quad Q>0 .
$$

Observe that $f_{n}(Q)$ is strictly decreasing in $Q$ for all $n$. For a fixed $n \in\{1, \ldots, N\}$, there is a unique $Q^{\star, n}$ such that $f_{n}\left(Q^{\star, n}\right)=S^{(n)}$ which is given by

$$
Q^{\star, n}=\frac{n \alpha-S^{(n)}}{2 \beta+(n-1) \gamma} .
$$

For each $n$, we have the following $n$-player candidate equilibrium:

$$
q_{i}^{\star, n}=\left\{\begin{array}{cl}
\frac{\bar{P}\left(Q^{\star, n}\right)-s_{i}}{2 \beta-\gamma} & \text { for } 1 \leq i \leq n, \\
0 & \text { for } n+1 \leq i \leq N,
\end{array}\right.
$$

where $Q^{\star, n}$ is given in (17). We denote the corresponding prices by $p_{i}^{\star, n}$ using (3). In order to determine which of the candidate equilibria is the true equilibrium of the game, we first compute, for a given firm, the net revenue per unit as

$$
p_{i}^{\star, n}-s_{i}=\frac{\beta}{2 \beta-\gamma}\left(\bar{P}\left(Q^{\star, n}\right)-s_{i}\right) .
$$

The following lemma then follows directly.

Lemma 3.1. $q_{i}^{\star, n}<0$ if and only if $p_{i}^{\star, n}<s_{i}$.

Proof. See (18) and (19).

A given candidate equilibrium can fail to be a Nash equilibrium of the game if

(i) $q_{i}^{\star, n}<0$ for some $1 \leq i \leq n$, or

(ii) $s_{i}<p_{i}\left(q_{1}^{\star, n}, \ldots, q_{n}^{\star, n}, 0, \ldots, 0\right)$ for some $n+1 \leq i \leq N$.

Case (i) holds if and only if $s_{i}>\bar{P}\left(Q^{\star, n}\right)$. So the effective market price is too low for this player and they would be better off not producing at all. Thus, we should look for a Nash equilibrium with a smaller number of active players. We provide the following lemma before discussing the second case. 
Lemma 3.2. $s_{n}<p_{n}\left(q_{1}^{\star, n-1}, \ldots, q_{n-1}^{\star, n-1}, 0, \ldots, 0\right)$ if and only if $s_{n}<\bar{P}\left(Q^{\star, n-1}\right)$. In other words, Firm $n$ wishes to participate in the $(n-1)$-firm equilibrium if and only if $s_{n}<\bar{P}\left(Q^{\star, n-1}\right)$.

Proof. The result follows from the equivalence

$$
\begin{aligned}
p_{n}\left(q_{1}^{\star, n-1}, \ldots, q_{n-1}^{\star, n-1}, 0, \ldots, 0\right) & =\alpha-\beta(0)-\gamma \sum_{j=1}^{n-1} q_{j}^{\star, n-1} \\
& =\alpha-\gamma Q^{\star, n-1} \\
& =\bar{P}\left(Q^{\star, n-1}\right) .
\end{aligned}
$$

Case (ii) means that some firm $i \in\{n+1, \ldots, N\}$ could produce a strictly positive quantity and would receive a price strictly above cost from the market and therefore make a positive profit. Lemma 3.2 shows that this case occurs if and only if $s_{i}<\bar{P}\left(Q^{\star, n}\right)$. In this case we should look for a Nash equilibrium with a larger number of active players.

The procedure for determining the equilibrium is to start with the one firm equilibrium that consists of the lowest cost firm producing as a monopoly. We then consider whether Firm 2 wishes to participate. That is, we check if Case (ii) holds with $i=2$. If so, we ask if both wish to participate in the two-player candidate equilibrium. We continue in this manner until we run out of firms to add or additional firms do not wish to enter. This construction has similarities to the equilibrium constructions found in [5] and [14], in that there is a cutoff point below which firms produce and above which firms are costed out. We must however take care that this procedure terminates and that this is sufficient to determine a unique Nash equilibrium. We establish in the following lemma the necessary inductive step.

Lemma 3.3. Fix some $n<N$. We have $n$ and $(n+1)$-player candidate equilibria with total production quantities $Q^{\star, n}$ and $Q^{\star, n+1}$, respectively, and the individual firm production quantities given by (18) with the corresponding $Q^{\star}$. Then, Firm $n+1$ will want to be active in the $n$-firm equilibrium if and only if they want to be active in the $(n+1)$-firm equilibrium.

Proof. From Lemma 3.2 Firm $n+1$ wants to be active in the $n$-firm equilibrium if and only if $s_{n+1}<\bar{P}\left(Q^{\star, n}\right)$. Recall the definition of $Q^{\star, n}$ as the unique $Q$ which satisfies $f_{n}\left(Q^{\star, n}\right)=S^{(n)}$, where the $f_{n}$ are defined in (16) and are strictly decreasing for $Q>0$. One can show for $1 \leq n<N$ that $f_{n+1}\left(Q^{\star, n}\right)=S^{(n)}+\bar{P}\left(Q^{\star, n}\right)$, and therefore

$$
f_{n+1}\left(Q^{\star, n+1}\right)-f_{n+1}\left(Q^{\star, n}\right)=s_{n+1}-\bar{P}\left(Q^{\star, n}\right) .
$$

In a similar manner, one can show $f_{n}\left(Q^{\star, n+1}\right)=S^{(n+1)}-\bar{P}\left(Q^{\star, n+1}\right)$, and hence

$$
f_{n}\left(Q^{\star, n+1}\right)-f_{n}\left(Q^{\star, n}\right)=s_{n+1}-\bar{P}\left(Q^{\star, n+1}\right) .
$$

We then find

$$
\begin{aligned}
& s_{n+1}<\bar{P}\left(Q^{\star, n}\right) \Longleftrightarrow f_{n+1}\left(Q^{\star, n+1}\right)<f_{n+1}\left(Q^{\star, n}\right) \quad \text { from }(21), \\
& \Longleftrightarrow Q^{\star, n+1}>Q^{\star, n} \\
& \Longleftrightarrow f_{n}\left(Q^{\star, n+1}\right)<f_{n}\left(Q^{\star, n}\right) \\
& \Longleftrightarrow s_{n+1} \quad<\bar{P}\left(Q^{\star, n+1}\right) \quad \text { from }(22) \text {, }
\end{aligned}
$$

from which the conclusion follows. 
Corollary 3.1. Total candidate equilibrium quantity is strictly increasing from $n$ firms to $(n+1)$ firms if and only if Firm $(n+1)$ is active in the $(n+1)$-firm candidate equilibrium.

Proof. The corollary states: $Q^{\star, n+1}>Q^{\star, n}$ if and only if $q_{n+1}^{\star, n+1}>0$. The conclusion follows from the proof of the lemma as we have $s_{n+1}<\bar{P}\left(Q^{\star, n}\right) \Longleftrightarrow Q^{\star, n+1}>Q^{\star, n}$, and the lemma itself gives that this is equivalent to Firm $n+1$ being active in the $(n+1)$-firm candidate equilibrium.

Proposition 3.1. There exists a unique Nash equilibrium to the differentiated Cournot game. The unique equilibrium quantities are given by

$$
q^{\star}=\left(q_{1}^{\star, n^{\star}}, \ldots, q_{n^{\star}}^{\star, n^{\star}}, 0, \ldots, 0\right),
$$

where $q_{i}^{\star, n}$ is given in (18) and $n^{\star}$ is the number of active firms in equilibrium which is given by

$$
n^{\star}=\min \left\{n \in\{1, \ldots, N\}: Q^{\star, n}=\bar{Q}^{\star}\right\},
$$

with $\bar{Q}^{\star}=\max \left\{Q^{\star, n}: 1 \leq n \leq N\right\}$.

Proof. We know by supposition that Firm 1 will participate in the one-firm candidate equilibrium as $s_{1}<\alpha$. Hence $Q^{\star, 1}>0$. Suppose for some $n<N$ we have a candidate Nash equilibrium in which the first $n$ firms are active. If $s_{n+1}<\bar{P}\left(Q^{\star, n}\right)$, or equivalently if $Q^{\star, n+1}>Q^{\star, n}$, then from Lemma 3.3, Firm $n+1$ wishes to enter, and by the same lemma, he will participate in the $(n+1)$-firm equilibrium. Furthermore, as all the other $n$ firms have costs lower than or equal to Firm $n+1$, they will also be active in the $(n+1)$-firm equilibrium. Therefore, every candidate equilibrium with $n$ or fewer players cannot be a true equilibrium due to entry. We can proceed adding players until either no further players wish to enter or there are no further players. We have uniqueness by construction.

The explicit characterization of $n^{\star}$, the number of active firms in equilibrium comes from the fact that $Q^{\star, n}$ is strictly increasing in $n$ as firms enter. At some point, we may have $Q^{\star, n}=Q^{\star,(n-1)}$ if a firm is exactly indifferent between entering and not entering, i.e. $q_{n}^{\star, n}=0$, exactly. Such a firm is not considered active in the equilibrium. It may stay flat for a range of $n$ if there is a range of firms with identical costs all of which are indifferent between entering and not entering. Then, the sequence will be decreasing. Thus, $n^{\star}$ will be given by the first $n$ whose entry causes $Q^{\star, n}$ to hit its maximum $\bar{Q}^{\star}$. In other words, $n^{\star}=\min \left\{n \in\{1, \ldots, N\}: Q^{\star, n}=\bar{Q}^{\star}\right\}$.

We illustrate the behavior of $Q^{\star, n}$ in Figure 1. In this example, the number of active firms in equilibrium, $n^{\star}$, is 5 , while $N=9$. This figure was generated with $\alpha=1, \beta=0.5, \gamma=0.2$. We also set the vector of costs to $s=(0.25,0.27,0.35,0.6,0.6,0.67 \overline{4}, 0.67 \overline{4}, 0.72,0.85)$. Firms 4 and 5 have equal cost and as $Q^{\star, 5}>Q^{\star, 4}$, we know that both are active in equilibrium. We also note that Firms 6 and 7 have equal cost, greater than the cost of Firm 5, and are exactly indifferent between entering and not entering. We see this as $Q^{\star, 5}=Q^{\star, 6}=Q^{\star, 7}$. The shape of the curve appears to always be concave, although we have not explored whether this holds in general. The main important feature to note is that the curve is strictly increasing up to $n^{\star}$ and flat or decreasing after $n^{\star}$. 


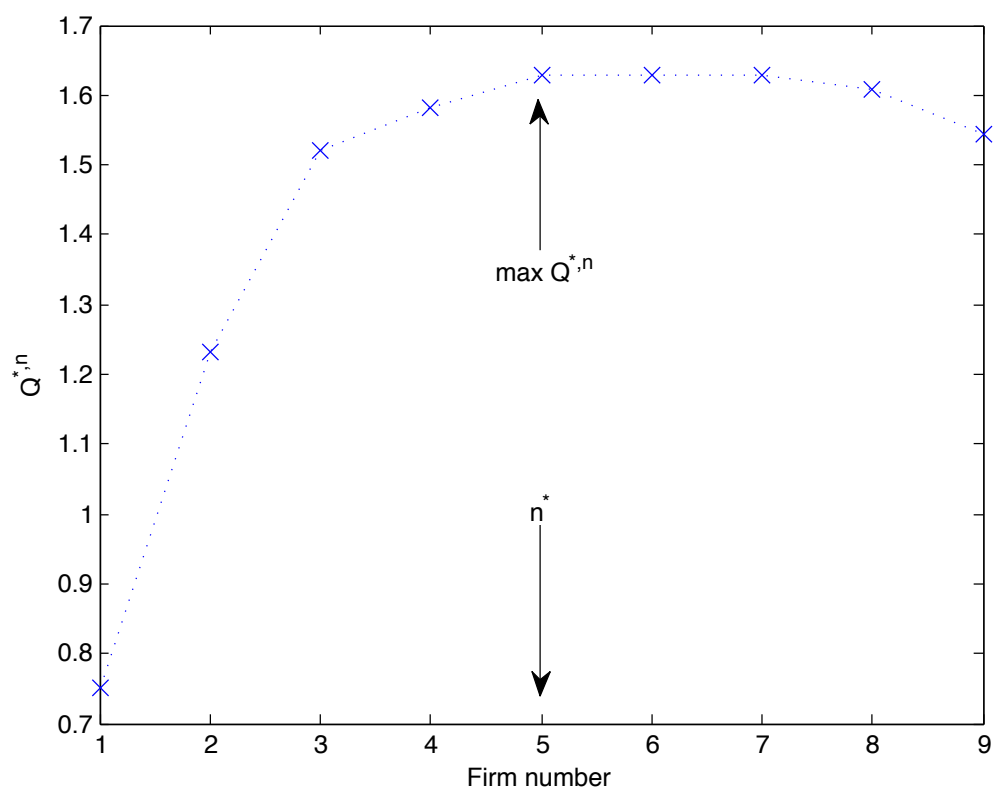

Figure 1: Illustrative behavior of $Q^{\star, n}$ and the number of active firms in equilibrium.

\subsection{Differentiated Bertrand Competition}

The profit function that the firms seek to maximize is again given in (10), where the firms now choose $p_{i}$ and quantities are given by $q_{i}(p)$ in (4). In addition, here we assume that if a firm receives zero demand in equilibrium, they set price equal to cost. The method of solution for this model is quite similar on the surface to the differentiated Cournot model. We can solve for the best-response functions of the firms and intersect these to obtain candidate Nash equilibria.

The reason for considering multiple different candidate equilibria is because, again, in the game with heterogeneous costs, the candidate equilibrium with all $N$ firms may result in negative demands for some firms. We must thus consider subgames which, for $n=1, \ldots, N$, involve only the first $n$ players. Let $p^{\star, n}=\left(p_{1}^{\star, n}, \ldots, p_{n}^{\star, n}, s_{n+1}, \ldots, s_{N}\right)$, where the first $n$ components solve the Nash equilibrium problem with profit functions as described above, where we replace $N$ with $n$ in the coefficients in the demand function $q_{i}(p)$ given in (4). These are given explicitly in (28).

Let $p^{\star}$ denote the vector of prices in equilibrium. It is shown in [23] that the Nash Equilibrium of the Bertrand game will be one of three types:

$\langle\mathrm{I}\rangle$ All $N$ firms price above cost. In this case, $p_{i}^{\star}>s_{i}$ for all $i=1, \ldots, N$, and the Nash equilibrium is simply the $N$-player interior Nash equilibrium given by $p^{\star}=\left(p_{1}^{\star, N}, \ldots, p_{N}^{\star, N}\right)$, where the $p_{i}^{\star, N}$ are as defined above.

$\langle\mathrm{II}\rangle$ For some $0 \leq n<N$, firms $1, \ldots, n$ price strictly above cost and the remaining firms set price equal to cost. In other words, $p_{i}^{\star}>s_{i}$ for $i=1, \ldots, n$, and $p_{j}=s_{j}$ for $j=n+1, \ldots, N$. The first $n$ firms play the interior $n$-player sub-game equilibrium as if firms $n+1, \ldots, N$ do not exist. These firms are completely ignorable because their costs are too high. The high cost firms receive zero demand and have prices fixed at cost by our definition of Nash equilibrium. 
The Nash equilibrium is $p^{\star}=\left(p_{1}^{\star, n}, \ldots, p_{n}^{\star, n}, s_{n+1}, \ldots, s_{N}\right)$.

$\langle$ III $\rangle$ For some $(k, n)$ such that $0 \leq k<n \leq N$, firms $1, \ldots, k$ price strictly above cost (if $k=0$ then no firms price strictly above cost), and the remaining firms set price equal to cost. In other words, $p_{i}^{\star}>s_{i}$ for $i=1, \ldots, k$ and $p_{j}^{\star}=s_{j}$ for $j=k+1, \ldots, N$.

Type $\langle\mathrm{III}\rangle$ differs from Type $\langle\mathrm{II}\rangle$ in that firms $k+1, \ldots, n$ are not ignorable: their presence is felt in the pricing decisions of firms $1, \ldots, k$, and we say that firms $k+1, \ldots, n$ are on the boundary. On the other hand, firms $n+1, \ldots, N$ are completely ignorable. This case arises when firms $k+1, \ldots, n$ would want to price above cost if they were ignored, but they do not want to price above cost in the full sub-game that includes them as a player.

Only an equilibrium of Type $\langle\mathrm{I}\rangle$ or Type $\langle\mathrm{II}\rangle$ is possible in the Cournot game. There we had Lemma 3.2 which resolved the fact that a firm whose quantity is negative in a candidate equilibrium does not wish to enter the game with a positive quantity if the remaining firms ignore this firm and play the candidate Nash equilibrium with one less player. However, in the Bertrand game, such a result does not hold.

Denote by $P^{\star, n}$ the sum of the $n$-firm candidate equilibrium prices. First, using the first-order conditions, we find

$$
P^{\star, n}=\frac{n \alpha(\beta-\gamma)+(\beta+(n-2) \gamma) S^{(n)}}{2 \beta+(n-3) \gamma} .
$$

Then, one can show that the condition for Firm $(n+1)$ to want to enter the game when the first $n$ firms price at the $n$-firm candidate equilibrium is equivalent to

$$
s_{n+1}<\frac{\alpha(\beta-\gamma)+\gamma P^{\star, n}}{(\beta-\gamma)+n \gamma}
$$

Furthermore, one can show that the condition that Firm $(n+1)$ wishes to participate in the $(n+1)$-firm candidate equilibrium at a price strictly above cost is equivalent to

$$
s_{n+1}<\frac{\alpha(\beta-\gamma)+\gamma P^{\star, n+1}}{(\beta-\gamma)+(n+1) \gamma} .
$$

In the Cournot game we had that these two conditions, wanting in and actually wanting to play, were equivalent. Here, they are not. It is the gap between these two conditions that gives rise to the Type $\langle\mathrm{III}\rangle$ equilibrium. As an example, set $\alpha=2, \beta=1, \gamma=0.999$. Then set $s=$ $(0.05,0.051,0.052,0.05252)$. We find that Firm 4 wants in as $s_{4}$ satisfies the condition in (26). However, Firm 4 does not actually want to play as $s_{4}$ violates $(27)$.

The lower cost firms would like to ignore the high cost firms on the boundary, alter their demand functions to remove these firms, and solve for a candidate equilibrium without these firms. However, this is not possible because the high cost firms would want back into the game. It is necessary and correct that the low cost firms alter their demand functions to remove these high cost firms. However, it is primarily this feature that gives rise to the Type 〈III $\rangle$ equilibrium in the Bertrand game. It is just one of the curiosities behind the Bertrand model. Contrarily, in the Cournot model, as firms get to directly choose demand with the market reacting through prices, nothing needs to be reallocated, and we can simply let a firm set quantity to zero and deal with the resulting inverse demands. 
Proposition 3.2 (Prop 2.6 in [23]). There exists a unique equilibrium to the Bertrand game with linear demand. The type $\langle I\rangle$ and $\langle I I\rangle$ candidate solutions are given by

$$
p_{i}^{\star, n}=\frac{1}{\left(2 b_{n}+c_{n}\right)}\left[a_{n}+c_{n} \frac{n a_{n}+b_{n} \sum_{m=1}^{n} s_{m}}{\left(2 b_{n}-(n-1) c_{n}\right)}+b_{n} s_{i}\right] .
$$

The type $\langle I I I\rangle$ candidate solutions are given by

$$
\begin{aligned}
p_{i}^{b, n+1, n+1-k}= & \frac{1}{\left(2 b_{n+1}+c_{n+1}\right)}\left[\left(a_{n+1}+c_{n+1} \sum_{m=k+1}^{n+1} s_{m}\right)\right. \\
& \left.+c_{n+1}\left(\frac{n\left(a_{n+1}+c_{n+1} \sum_{m=k+1}^{n+1} s_{m}\right)+b_{n+1} \sum_{m=1}^{k} s_{m}}{2 b_{n+1}-(k-1) c_{n+1}}\right)+b_{n+1} s_{i}\right],
\end{aligned}
$$

where the superscript $(b, n+1, n+1-k)$ stands for boundary, $(n+1)$ firms entering into the demand function, and $n+1-k$ firms on the boundary, i.e. not ignorable. The Nash equilibrium is constructed as follows:

- If $s_{1}>\frac{a_{1}}{b_{1}}$, then $p^{\star}=\left(s_{1}, \ldots, s_{N}\right)$. (Type $\langle I I\rangle$ with $\left.n=N\right)$.

- Else, find $n<N$ such that $p_{i}^{\star, n}>s_{i}, \forall i=1, \ldots, n$, and $p_{n+1}^{\star, n+1} \leq s_{n+1}$.

- If $s_{n+1} \geq b_{n+1}^{-1}\left(a_{n+1}+c_{n+1} \sum_{i=1}^{n} p_{i}^{\star, n}\right)$, then $p^{\star}=\left(p_{1}^{\star, n}, \ldots, p_{n}^{\star, n}, s_{n+1}, \ldots, s_{N}\right)$, (Type $\langle I I\rangle$ with $n<N)$,

- Else,

○ if $p_{n}^{b, n+1,1}>s_{n}$, then $p^{\star}=\left(p_{1}^{b, n+1,1}, \ldots, p_{n}^{b, n+1,1}, s_{n+1}, \ldots, s_{N}\right)$, (Type $\left.\langle I I I\rangle\right)$,

$\circ$ else, find $k<n$ such that

$$
\begin{gathered}
p_{i}^{b, n+1, n+1-k}>s_{i} \text { for all } i=1, \ldots, k, \text { and } p_{k+1}^{b, n+1, n+1-(k+1)}<s_{k+1} . \\
\text { Then } \left.p^{\star}=\left(p_{1}^{b, n+1, n+1-k}, \ldots, p_{k}^{b, n+1, n+1-k}, s_{k+1}, \ldots, s_{N}\right) \text {. (Type }\langle\text { III }\rangle\right) .
\end{gathered}
$$

Proof. The proof can be found in [23].

Note, we also proved the existence of a unique Nash equilibrium to the Bertrand game with more general demand functions in [23].

\subsection{Homogeneous Cournot Competition}

Similar to the differentiated Cournot model, firms use quantity as their strategic variable to maximize (10) where price $p_{i}^{H}(q)$ is given in (8). We note that as price is only a function of the aggregate quantity $Q$, we in fact have the price function $P(Q):=p_{i}^{H}(Q)$, where the latter function is a slight abuse of notation of the previously defined price function. This model was studied extensively in 
the setting of general inverse demand functions in [16]. There, the essential piece of information about the price function was the relative prudence curve denoted by $\rho(Q)$ and defined by

$$
\rho(Q):=-\frac{Q P^{\prime \prime}}{P^{\prime}}
$$

The standard definition of relative prudence is given by

$$
\rho(Q)=-\frac{Q U^{\prime \prime \prime}(Q)}{U^{\prime \prime}(Q)}
$$

where the utility of a consumer is given by the quasilinear utility function $U(Q)+m$ where $Q$ is the quantity consumed and $m$ is money. However, we see immediately that these definitions are equivalent based on our derivation of $p_{i}^{H}(q)$ in Section 2.2 .

For the linear price function $\rho(Q) \equiv 0$. The calculation of the Nash equilibrium is identical to that of the differentiated case, except here instead of using the effective market price function $\bar{P}(Q)$, we use the actual market price function $P(Q)=p^{H}(Q)$. With this slight modification all of the results in Section 3.1 carry over to this setting, provided we set $\beta=\gamma$.

As we shall require it later, we note, setting $\gamma=\beta$ in (17), that the equilibrium total supply in the homogeneous model is given by

$$
Q_{H}^{\star, n}=\frac{n \alpha-S^{(n)}}{(n+1) \beta} .
$$

Here we use the subscript $H$ to stand for Homogeneous in order to discriminate this quantity from the one used in the differentiated Cournot game.

We then have the following result that fully characterizes the equilibrium. The proof follows the proof of Proposition 3.1 with $\gamma=\beta$.

Proposition 3.3 (Corr 2.7 in [16]). The unique Nash equilibrium can be constructed as follows. Let $\bar{Q}_{H}^{\star}=\max \left\{Q_{H}^{\star, n} \mid 1 \leq n \leq N\right\}$. Then the unique Nash equilibrium quantities are given by

$$
q_{i}^{\star}(s)=\max \left\{\frac{\alpha-\beta \bar{Q}_{H}^{\star}-s_{i}}{\beta}, 0\right\}, \quad 1 \leq i \leq N .
$$

The number of active players in the unique equilibrium is $m=\min \left\{n \mid Q_{H}^{\star, n}=\bar{Q}_{H}^{\star}\right\}$.

\subsection{Homogeneous Bertrand Competition}

The homogeneous Bertrand case is perhaps the simplest and yet most difficult to analyze of the four models. As in the differentiated Bertrand case, the firms use price as their strategic variable in maximizing the profit function in (10) with quantity given by $q_{i}^{H}(p)$ in (9). The difficulty arises from the non-smoothness of the demand function. If one firm sets a price slightly below the rest of the market, then they will receive all the demand. If another firm were to charge an even slightly lower price than this, then all of the demand would shift to this new lowest cost firm. This behavior makes the result seemingly very simple.

Consider first the case of a duopoly. We illustrate in Figure 2 the best response functions for the two firms, where $s_{1}<s_{2}$. The best response is to charge cost while your opponent is pricing below 


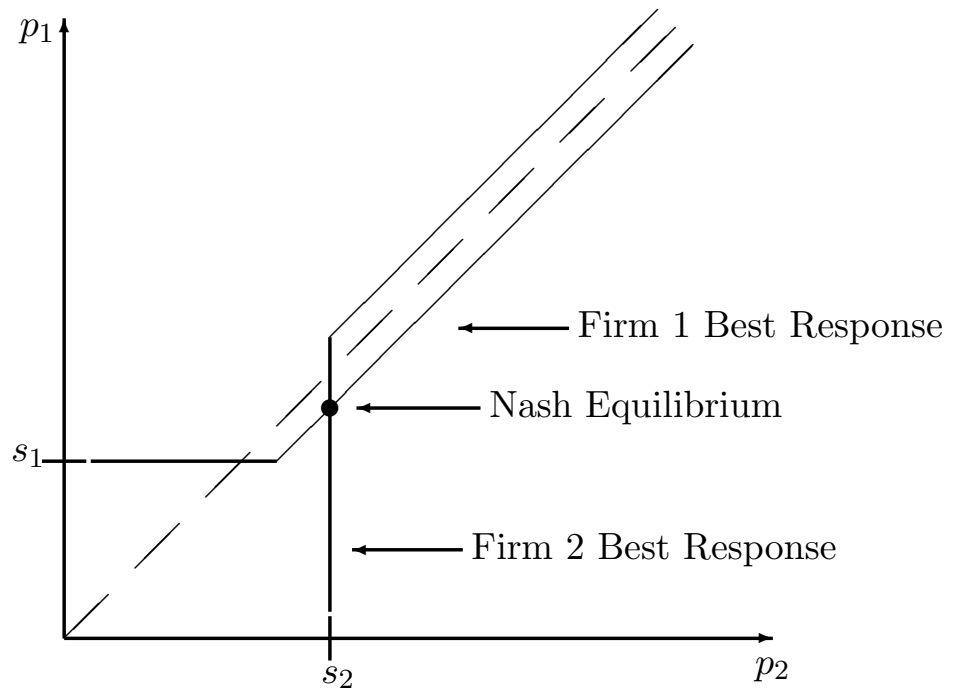

Figure 2: Best Response Functions for Homogeneous Bertrand Duopoly

your cost, and then to price at your opponent's price minus a small amount, which we denote informally as $p^{\star}=\left(s_{2}-\epsilon, s_{2}\right)$. The reason for this is that if Firm 1 were to price strictly at $s_{2}$, by any amount, Firm 2 would have an incentive to deviate from sharing demand at this price by lowering price by a small amount and thereby capture the entire market at a price above cost. The same concept extends to $N$ firms in the sense that the lowest cost firm is the only one who ever receives demand from the market.

There is a subtle issue here as, for a fixed value of $\epsilon>0$, Firm 1 would always be better off decreasing $\epsilon$ by a small amount and therefore increasing profit. This is what has been referred to as the open-set problem, see [9] and references therein. We follow their solution of such a situation and assume that the equilibrium exists in the limiting sense of Firm 1 setting price equal to $s_{2}$ and obtaining the entire market demand at this price, while Firm 2 sells nothing and gets zero profit. Further, we have assumed throughout in a Bertrand market that any firm with zero demand in equilibrium at any price greater or equal to cost sets price equal to cost. Thus, we have an unique equilibrium (albeit in a limiting sense) of $p^{\star}=\left(s_{2}, s_{2}\right)$, with Firm 1 supplying the whole market.

If Firm 1 knew they were the only firm in the market, then they would charge their optimal monopoly price

$$
p_{M}^{\star}=\frac{1}{2}\left(\alpha+s_{1}\right) .
$$

This is greater than cost provided $s_{1}<\alpha$. If there are other firms in the market, Firm 1 cannot necessarily choose this price, because if they did, other firms would have an incentive to undercut that price and capture all of the demand in the market. In fact, one can show that no equilibrium is sustainable with $p_{1}>s_{2}$, regardless of the number of firms in the market. Furthermore, for $\epsilon>0$ small enough, we have that the profit of Firm 1 from setting $p_{1}=s_{2}-\epsilon$ is strictly greater than the profit from setting $p_{1}=s_{2}$ and sharing demand with Firm 2. As above, we deal with this situation in a limiting sense and simply use $s_{2}$ in place of $s_{2}-\epsilon$, where it is understood that Firm 1 serves the entire market. Hence,

$$
p_{1}^{\star}=\min \left(s_{2}, p_{M}^{\star}\right)
$$


and

$$
p^{\star}=\left(p_{1}^{\star}, s_{2}, s_{3}, \ldots, s_{N}\right) .
$$

The expression in (33) is the analog of the Type $\langle\mathrm{III}\rangle$ equilibrium from the differentiated Bertrand game. Firm 2 can be on the boundary, with Firm 1 pricing below his monopoly price because they must respect the presence of Firm 2. However, if the cost of Firm 2 is high enough, then Firm 1 can completely ignore the higher cost firms and we are in the setting analogous to a Type $\langle$ II $\rangle$ equilibrium.

The only subtlety that arises in this case is what occurs when firms have equal cost. Obviously this is only relevant if the firms that are tied also have the lowest costs in the market. Suppose for some $k>1$ we have $s_{1}=s_{2}=\cdots=s_{k}$ and $s_{k}<s_{k+1} \leq s_{k+2} \leq \cdots \leq s_{N}$. Due to the potential for undercutting, the only equilibrium is for all firms to set price equal to marginal cost. This can be seen by comparing the profit at any other equilibrium price and that obtained by a single firm deviating slightly and capturing the entire market. Hence,

$$
p^{\star}=\left(s_{1}, \ldots, s_{1}, s_{k+1}, \ldots, s_{N}\right),
$$

where it is understood that Firms 1 through $k$ split demand equally and the remaining firms get zero demand and make zero profit.

\subsection{Equal Costs}

Suppose the $N$ firms all have equal costs, that is $s:=s_{1}=\cdots=s_{N}$. This is just a base case for comparison and has already been thoroughly studied. First, we can state that provided $s$ is small enough, which will be made explicit below, all firms will produce in the equilibrium. Moreover, as our specification of demand is symmetric across firms, the equilibrium is unique and symmetric.

\begin{tabular}{|cc|c|c|}
\cline { 3 - 3 } Differentiated & Cournot & Price & Quantity \\
\cline { 3 - 4 } & & $\frac{\alpha \beta+s(\beta+(N-1) \gamma)}{2 \beta+(N-1) \gamma}$ & $\frac{\alpha-s}{2 \beta+(N-1) \gamma}$ \\
Homogeneous & Cournot & $\frac{\alpha(\beta-\gamma)+(\beta+(N-2) \gamma) s}{2 \beta+(N-3) \gamma}$ & $\frac{\beta+(N-2) \gamma}{2 \beta+(N-3) \gamma}\left(\frac{\alpha-s}{\beta+(N-1) \gamma}\right)$ \\
& Bertrand & $\frac{\alpha}{N+1}+\frac{N}{N+1} s$ & $\frac{\alpha-s}{\beta(N+1)}$ \\
\cline { 3 - 4 } & $s$ & $\frac{\alpha-s}{\beta N}$ \\
\hline
\end{tabular}

Table 1: Equilibrium Prices and Quantities for equal cost oligopoly

From Table 1 we can see that the condition for an equilibrium with positive quantities and prices is that $s<\alpha$. The homogeneous formulas are the easiest to analyze. We see that under the condition $s<\alpha$, homogeneous Cournot price is greater than homogeneous Bertrand price, however they are equal in the limit as $N \rightarrow \infty$. Moreover, the market quantity, $Q$, is greater in the homogeneous Bertrand game compared to the homogeneous Cournot game. Again, these are equal in the limit. One can also show that these inequalities hold in the differentiated cases as well. That is, $P_{\text {Cournot }}>P_{\text {Bertrand }}$ and $Q_{\text {Bertrand }}>Q_{\text {Cournot }}$. Moreover, the closer $\gamma / \beta$ is to one, the greater these differences are. 


\section{How many firms are active?}

In this section we consider the question of whether a firm is active or inactive in equilibrium. We first provide a three-firm game example to illustrate the possibilities that can arise. Then, we move to the more general case of $N$-firm games. The main result of this section is an ordering of the number of active firms in equilibrium across the four different types of games. Following the analytic result, we provide numerical examples to demonstrate the various prospective outcomes.

\subsection{Three-Firm Games}

In order to fix some ideas we consider the case of two firms ordered such that $0<s_{1}<s_{2}$. One can easily characterize the equilibria that result in the four types of oligopolies we are discussing. However, let us consider the addition of a third firm with cost $s_{3}$. We have five possibilities: (i) $s_{3}<s_{1}$, (ii) $s_{1}=s_{3}$, (iii) $s_{1}<s_{3}<s_{2}$, (iv) $s_{2}=s_{3}$, and (v) $s_{2}<s_{3}$. The question we pose is what effect does this third firm have on the market equilibrium. Obviously one can choose costs in such a manner so that we have any number of active firms in equilibrium in all four different types of oligopolies.

We fix $s_{1}=0.1, s_{2}=0.2, \alpha=1, \beta=0.5$ and $\gamma=0.1$. We then let $s_{3}$ vary from 0.001 to 0.999 . We display the prices of the three firms over the range of costs of Firm 3 in the four different types of oligopoly in Figures 3(a) - 4(b). We display the number of active firms in the different types of oliogopoly in Figure 5. The prices of all firms are strictly increasing in the cost of Firm 3, except in homogeneous Bertrand, while this firm is active in the equilibrium. After Firm 3 is no longer in the equilibrium, the prices of the remaining active firms are flat as this high cost firm is no longer relevant to the market. The only exception is in the differentiated Bertrand market where the prices of Firms 1 and 2 increase over a small region of the cost space where Firm 3 is on the boundary until it reaches a point where Firm 3 is completely ignorable and the prices then level off.

As $\gamma$ is small relative to the size of $\beta$, we have that the goods are highly differentiated. Thus, there should be large differences between the homogeneous and differentiated models. This is observed in Figure 5 where the homogeneous Cournot model has a far different profile of the number of active firms compared with the differentiated Cournot model. Similarly between the homogeneous and differentiated Bertrand models. One can also see that the differentiated Bertrand and Cournot markets are quite close in terms of the number of active firms. We shall return to this feature in what follows.

\subsection{The General Case: N-Firm Games}

Fix the total number of firms $N$, the parameters $\alpha, \beta$, and $\gamma$, and the vector of costs $s=\left(s_{1}, \ldots, s_{N}\right)$ such that $0<s_{1} \leq s_{2} \leq \cdots \leq s_{N}<\alpha$.

We shall denote by $n_{B h}^{\star}, n_{B d}^{\star}, n_{C h}^{\star}, n_{C d}^{\star}$, the number of active firms in equilibrium in the homogeneous Bertrand game, differentiated Bertrand game, homogeneous Cournot game and differentiated Cournot game, respectively. The purpose of this section is to show specifically how these numbers 


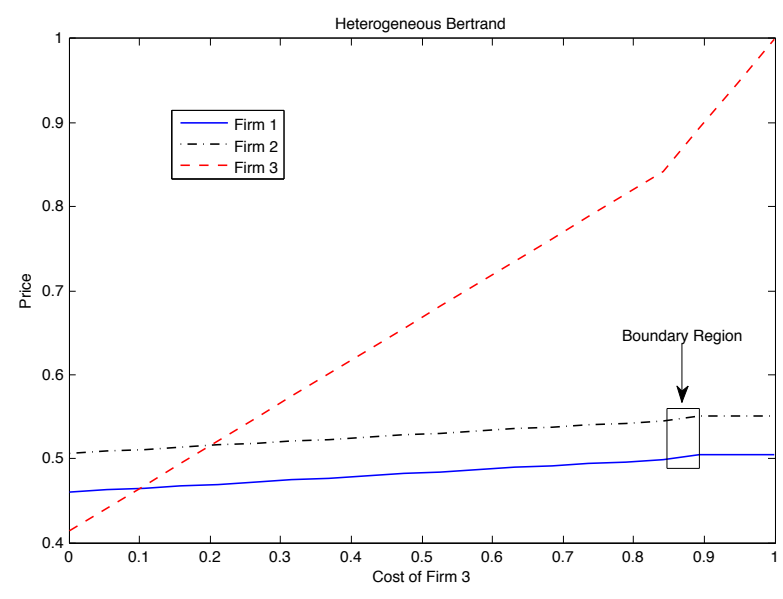

(a) Bertrand

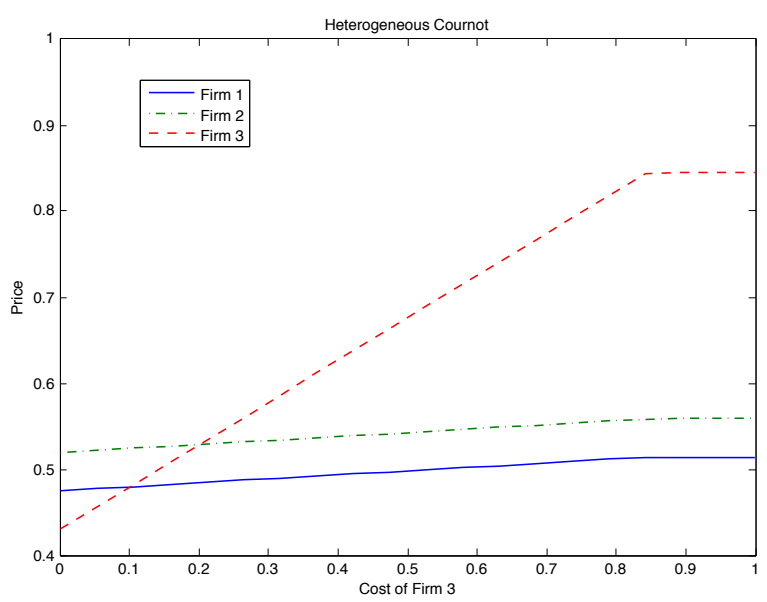

(b) Cournot

Figure 3: Differentiated Models - Prices

relate to one another. This will be shown in Theorem 4.1, but first we establish a few helpful lemmas. In the process we shall need the quantity $\theta_{n}=(\beta-\gamma)\left(\frac{2 \beta+(n-1) \gamma}{\beta+(n-2) \gamma}\right)$.

Recall the fact that in both Cournot type games, a firm is active in equilibrium, if and only if the total equilibrium supply strictly increases when this firm enters the market. In the homogeneous Cournot game, this amounts to the fact that Firm $n$ is active if and only if $Q_{H}^{\star, n}>Q_{H}^{\star, n-1}$. In the differentiated Cournot game, the condition is $Q^{\star, n}>Q^{\star, n-1}$ if and only if Firm $n$ is active in equilibrium. We characterize these conditions in terms of the cost of the firms in the following lemma.

Lemma 4.1. In the homogeneous Cournot game, we have $Q_{H}^{\star, n}>Q_{H}^{\star, n-1}$ if and only if $s_{n}<$ $\frac{\alpha+S^{(n-1)}}{n}$. In the differentiated Cournot game, we have $Q^{\star, n}>Q^{\star, n-1}$ if and only if $s_{n}<\frac{\alpha(2 \beta-\gamma)+\gamma S^{(n-1)}}{(2 \beta-\gamma)+(n-1) \gamma}$.

Proof. For the homogeneous case, recall the definition of $Q_{H}^{\star, n}$ in (30). Write down $Q_{H}^{\star, n}-Q_{H}^{\star, n-1}$ and rearrange. The differentiated case can be found in Corollary 3.1, where we note that $s_{n}<\bar{P}\left(Q^{\star, n}\right)$ is equivalent to the given condition.

Lemma 4.2. The following expression is increasing in $h$

$$
\frac{\alpha h+\gamma S^{(n-1)}}{h+(n-1) \gamma}
$$

provided the denominator is not zero.

Proof. Take a derivative with resect to $h$ to obtain

$$
\frac{\partial}{\partial h}\left[\frac{\alpha h+\gamma S^{(n-1)}}{h+(n-1) \gamma}\right]=\frac{1}{(h+(n-1) \gamma)^{2}}\left(\alpha \gamma(n-1)-\gamma S^{(n-1)}\right) .
$$

As $\gamma$ is strictly positive, we find that this expression is strictly positive provided $(n-1) \alpha>S^{(n-1)}$. This is obviously true based on the assumption that $s_{i}<\alpha$ for all $i$. 


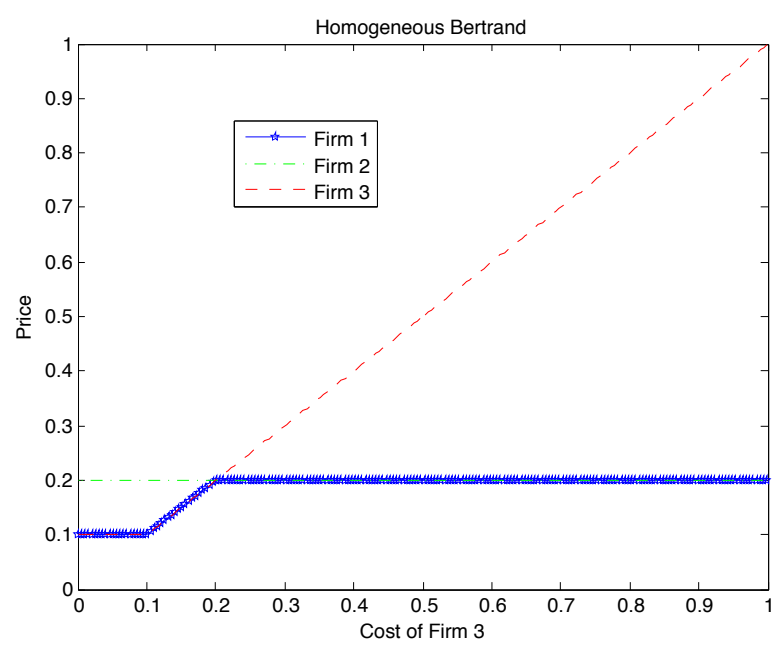

(a) Bertrand

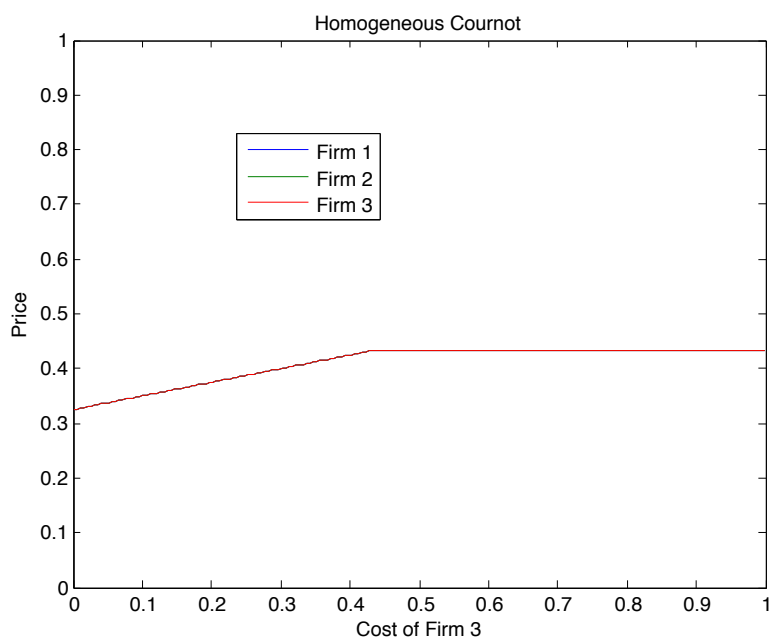

(b) Cournot

Figure 4: Homogeneous Models - Prices

Lemma 4.3. $(2 \beta-\gamma)>\theta_{n}$ for all $n>1$.

Proof.

$$
\begin{aligned}
2 \beta-\gamma-\theta_{n} & =2 \beta-\gamma-(\beta-\gamma)\left(\frac{2 \beta+(n-1) \gamma}{\beta+(n-2) \gamma}\right) \\
& =\gamma\left(\frac{(n-2) \beta+\gamma}{\beta+(n-2) \gamma}\right) .
\end{aligned}
$$

Obviously the expression in (38) is positive for $n>1$.

Theorem 4.1. $n_{B h}^{\star} \leq n_{C h}^{\star} \leq n_{C d}^{\star}$. Further, $n_{B d}^{\star} \leq n_{C d}^{\star}$. Finally, $n_{C h}^{\star} \geq n_{B d}^{\star}$ if $\theta_{n_{C h}^{\star}}<\gamma$.

Proof. $\underline{n_{B h}^{\star} \leq n_{C h}^{\star}}$

First, we note that $n_{B h}^{\star}=\#\left\{k: s_{k}=\min _{i} s_{i}\right\}$. Thus, this is equal to one unless we have for some $j, 0<s_{1}=\cdots=s_{j}<s_{j+1} \leq s_{j+2} \leq \cdots \leq s_{N}$. In such a case, we would have $n_{B h}^{\star}=j$. We know that $Q_{H}^{\star, 1}>0$ by assumption on $s_{1}<\alpha$. Furthermore, with the above specification for the costs, simple algebra shows

$$
Q_{H}^{\star, j}=2\left(\frac{j}{j+1}\right) Q_{H}^{\star 1}
$$

Moreover, $2\left(\frac{j}{j+1}\right)>1$ if and only if $j>1$. Hence, $Q_{H}^{\star, j}>Q_{H}^{\star, 1}$ for all $j>1$. Therefore at least all firms with cost equal to the lowest cost firm are active in the homogeneous Cournot equilibrium. In this case, this means $n_{C h}^{\star} \geq j$. Therefore, $n_{B h}^{\star} \leq n_{C h}^{\star}$.

$\underline{n_{C h}^{\star} \leq n_{C d}^{\star}}$

Lemma 4.1 specifies that firm $n$ participates in the homogeneous Cournot equilibrium if

$$
s_{n}<\frac{\alpha+S^{(n-1)}}{n}=\frac{\alpha \gamma+\gamma S^{(n-1)}}{\gamma+(n-1) \gamma},
$$




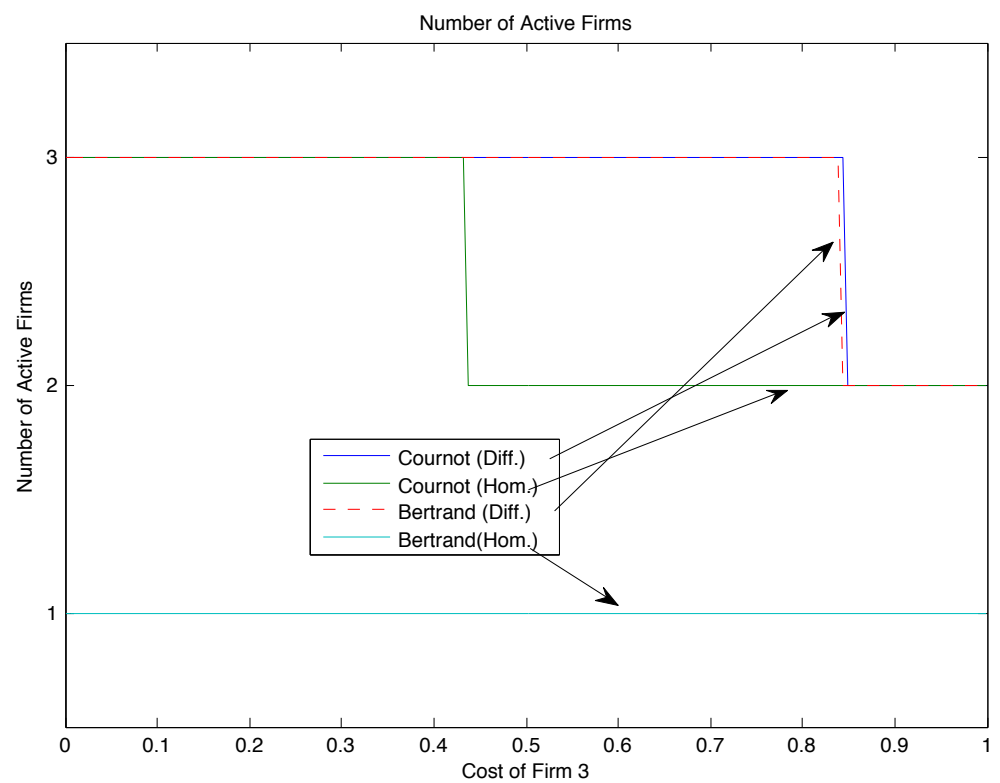

Figure 5: Number of Active Firms

and this firm participates in the differentiated Cournot equilibrium if

$$
s_{n}<\frac{\alpha(2 \beta-\gamma)+S^{(n-1)}}{2 \beta+(n-2) \gamma} .
$$

Using Lemma 4.2, we have

$$
\frac{\alpha(2 \beta-\gamma)+S^{(n-1)}}{(2 \beta-\gamma)+(n-1) \gamma}>\frac{\alpha \gamma+\gamma S^{(n-1)}}{\gamma+(n-1) \gamma}
$$

because $(2 \beta-\gamma)>\gamma$. Hence, if Firm $n$ is active in the homogeneous Cournot equilibrium, i.e. if their cost is low enough, then the firm is also active in the differentiated Cournot equilibrium by (42). Therefore, $n_{C h}^{\star} \leq n_{C d}^{\star}$.

$\underline{n_{B d}^{\star} \leq n_{C d}^{\star}}$

The differentiated Bertrand equilibrium can be of three types. In Type $\langle\mathrm{I}\rangle$, we have that all firms price above cost according to their interior candidate equilibrium prices $p_{i}^{\star, N}$. It is obvious that $p_{N}^{\star, N}>s_{N}$ is necessary and sufficient for this equilibrium to hold. This condition on $s_{N}$ is equivalent to

$$
s_{N}<\frac{\alpha \theta_{N}+\gamma S^{(N-1)}}{\theta_{N}+(N-1) \gamma} .
$$

Using Lemmas 4.2 and 4.3 , we find that

$$
\frac{\alpha \theta_{N}+\gamma S^{(N-1)}}{\theta_{N}+(N-1) \gamma}<\frac{\alpha(2 \beta-\gamma)+S^{(N-1)}}{(2 \beta-\gamma)+(N-1) \gamma} .
$$

This implies that if there is a Type $\langle\mathrm{I}\rangle$ equilibrium in the differentiated Bertrand game, i.e. $n_{B d}^{\star}=$ $N$, then we also have $n_{C d}^{\star}=N$. 
If we a priori know that we have an equilibrium of Type $\langle\mathrm{II}\rangle$, then we know that Firm $n$ is active in the differentiated Bertrand equilibrium if

$$
s_{n}<\frac{\alpha \theta_{n}+\gamma S^{(n-1)}}{\theta_{n}+(n-1) \gamma},
$$

and the firm is active in the differentiated Cournot equilibrium if

$$
s_{n}<\frac{\alpha(2 \beta-\gamma)+S^{(n-1)}}{(2 \beta-\gamma)+(n-1) \gamma} .
$$

Again using Lemmas 4.2 and 4.3, we find the same inequality as (44) with $N$ replaced by $n$. Hence, a firm being active in the Type $\langle$ II $\rangle$ differentiated Bertand equilibrium implies the firm is active in the differentiated Cournot equilibrium. So for a Type $\langle\mathrm{II}\rangle$ equilibrium, we have $n_{B d}^{\star} \leq n_{C d}^{\star}$.

Finally, the situation of a Type $\langle\mathrm{III}\rangle$ equilibrium could arise. However, this serves only to decrease the number of active firms in the market from the maximum number of firms that could be sustained in a Type $\langle\mathrm{II}\rangle$ equilibrium. That is, a Type $\langle\mathrm{III}\rangle$ equilibrium starts with a Type $\langle\mathrm{II}\rangle$ equilibrium and then possibly removes some firms from being active. Therefore, in all cases we have $n_{B d}^{\star} \leq n_{C d}^{\star}$.

$\underline{n_{C h}^{\star} \text { vs } n_{B d}^{\star}}$

Let us ignore for now the case of a Type $\langle\mathrm{III}\rangle$ equilibrium in the differentiated Bertrand game. We have established the conditions on $s_{n}$ for a firm to be active in the two types of equilibria. First, in the homogeneous Cournot case we have the condition given in (40). Second, in a Type $\langle\mathrm{I}\rangle$ or Type $\langle\mathrm{II}\rangle$ equilibrium in the differentiated Bertrand game, we have the condition given in (45). We find by Lemma 4.2 that Firm $n$ being active in the differentiated Bertrand game implies the firm is active in the homogeneous Cournot game if $\theta_{n_{C h}^{\star}}<\gamma$. Therefore, this implies $n_{B d}^{\star} \leq n_{C h}^{\star}$. This result continues to hold for a Type $\langle$ III $\rangle$ equilibrium as again such an equilibrium only serves to reduce $n_{B d}^{\star}$.

Remark 4.1. If $\theta_{n_{B d}^{\star}}>\gamma$ then the relative size of the conditions on cost reverses and therefore one expects $n_{C h}^{\star} \leq n_{B d}^{\star}$ to hold. However, this does not account for the possibility of a Type $\langle$ III $\rangle$ equilibrium. The number of active firms in a Type $\langle$ III $\rangle$ equilibrium is highly sensitive to the costs and it is quite difficult to ascertain what occurs in this case. However, Type $\langle$ III $\rangle$ equilibrium are rare in some sense in that they only occur for very special specifications of the costs. Therefore, in most situations, one should have $n_{C h}^{\star} \leq n_{B d}^{\star}$ if $\theta_{n_{B d}^{\star}}>\gamma$.

Remark 4.2. The condition $\theta_{n}>\gamma$ essentially boils down to $\gamma$ being small enough relative to $\beta$. In fact, one can show that $\theta_{n}-\gamma=(2 \beta+n \gamma)(\beta-2 \gamma)+3 \gamma^{2}$. Thus, a sufficient condition for this to be positive is $\beta>2 \gamma$. Moreover, what happens as $\gamma$ approaches $\beta$ is that the homogeneous Cournot and the differentiated Cournot approach one another, and similarly with the two Bertrand models. However, as the homogeneous Bertrand model always has only one active firm in the market (when there is a unique low cost firm) and the differentiated Cournot model has the most active, we find that the differentiated Bertrand and homogeneous Cournot have to cross over at some point to account for this lack of differentiation among the goods. Thus, informally, one can claim that for sufficiently differentiated products we have: $n_{B h}^{\star} \leq n_{C h}^{\star} \leq n_{B d}^{\star} \leq n_{C d}^{\star}$.

Remark 4.3. If we let $\gamma=0$, then the differentiated Bertrand and Cournot models coincide in terms of the number of active firms. This can be seen from (45) and (46), as setting $\gamma=0$ causes $\theta_{n}=2 \beta$ and the conditions on cost for a firm to be active in equilibrium in the two cases then 
coincides. Also, based on the assumption that $s_{i}<\alpha$ for all $i$, we will have all firms active in the equilibrium that results with $\gamma=0$. This is all fairly obvious but at least worthwhile to note as the behavior of the number of active firms in equilibrium depends highly on $\gamma$ and there is no difference between differentiated Bertrand and Cournot when goods are independent.

\subsection{Numerical Examples}

Fix $s=(0.25,0.27,0.35,0.4,0.5), \alpha=1$ and $\beta=0.5$. We then consider the addition of another firm to the market with cost $s_{6}$ varying from 0.001 to 0.999 . We consider three different possible values of $\gamma$, a low, base and high case. The low and high cases for the four different oligopoly models are displayed in Figure 6 (a) and (b). The results for the base case of $\gamma=0.3$ are displayed in Figure 7.

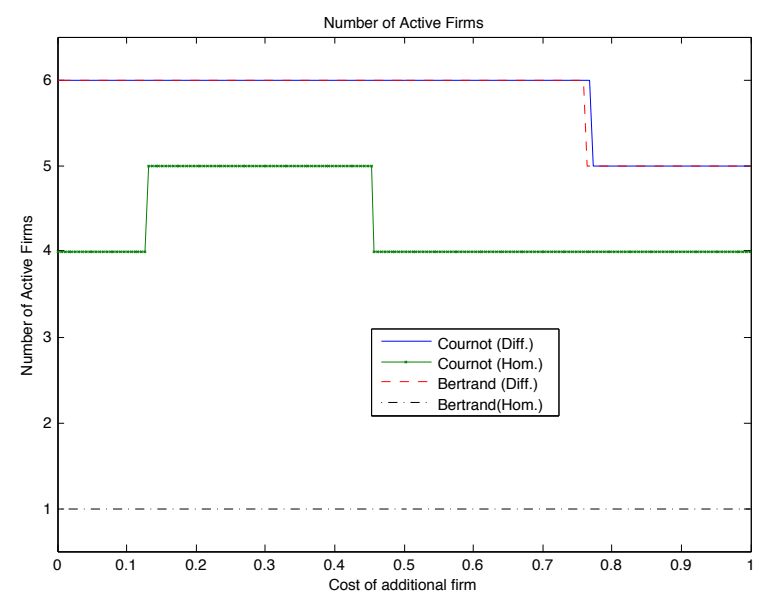

(a) Low, $\gamma=0.1$

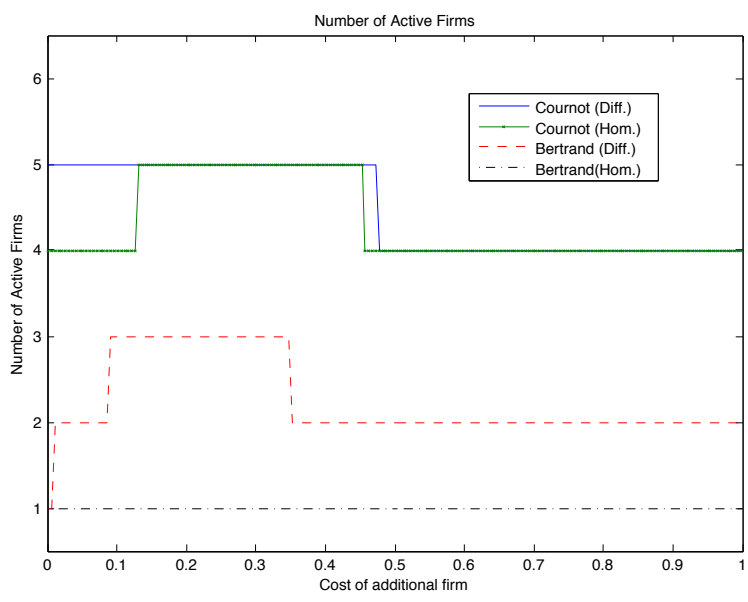

(b) High, $\gamma=0.45$

Figure 6: Number of Active Firms - 6 firm example

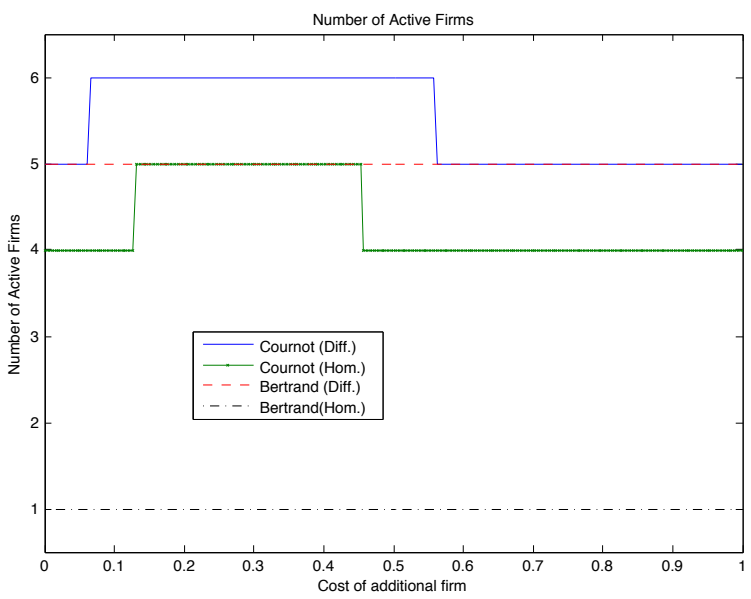

Figure 7: Number of Active Firms - 6 firm example, $\gamma=0.3$

In the high case, we see that increasing $\gamma$ this much towards $\beta$ causes the number of active firms in the differentiated Bertrand market to be less than that of the homogeneous Cournot market. We 
also see that the homogeneous and differentiated Cournot markets have similar numbers of active firms, coinciding over a large region of the cost of the additional firm, contrary to the result in Figure 7 where they are completely separated over the whole space of costs.

In the low case representing the other extreme point of view where we move $\gamma$ towards zero, we see that the differentiated Bertrand and Cournot are almost identical with Cournot having more firms over a small region of the space of costs. We also see that the homogeneous Cournot is completely separated from the three other models of oligopoly.

Another point of view from which we can study the behavior of the effect of the degree of product differentiation on the market equilibrium is to plot the number of active firms in the four different market types versus the ratio $\gamma / \beta$. We fix the total possible number of firms at 40 , we set $\alpha=1$, and finally we fix $\beta=0.5$. We then vary $\gamma$ so that $\gamma / \beta$ ranges from 0 to 1 .

First, we set $s_{1}=0.1$ and $s_{40}=0.99$, and specify the costs of the intermediate firms to be linearly increasing from $s_{1}$ to $s_{40}$ so that the difference between the costs of adjacent firms is constant. We display this in Figure 8 (a).

Next, we put firms into 5 groups so that there are 8 firms with equally spaced costs within each group, the costs varying from lowest to highest by 0.005 , then with a gap of 0.18 between groups. For example, the first group has $s_{1}=0.1, s_{2}=0.105, s_{3}=0.110, \ldots, s_{8}=0.135$; then $s_{9}=0.315$. We continue in this manner until we get to $s_{40}=0.995$. We display the results with this cost structure in Figure 8 (b).

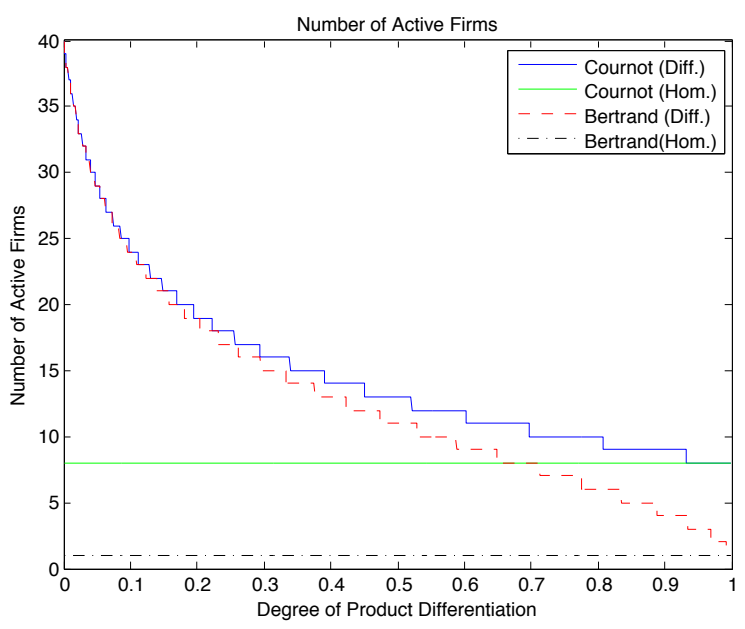

(a) Evenly spaced costs

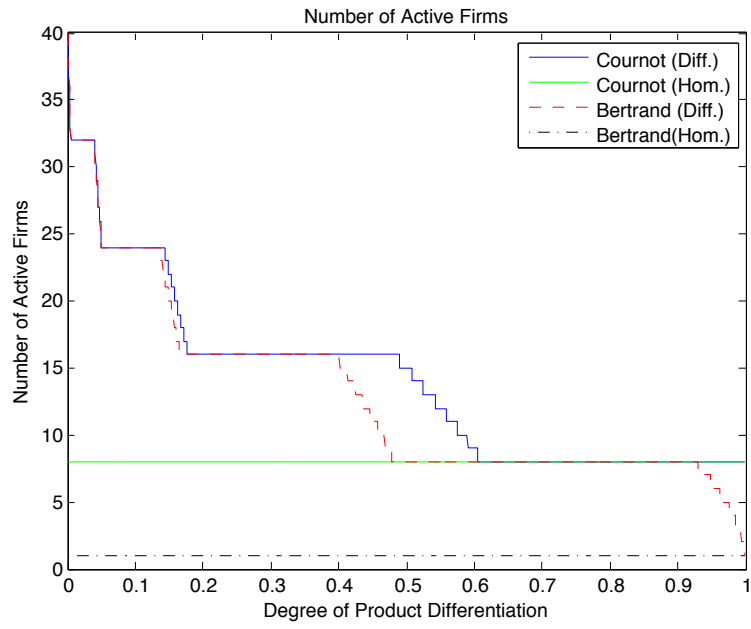

(b) Five different cost clusters

Figure 8: Number of Active Firms - 40 firm example

One can clearly see from both figures that the number of active firms in equilibrium is decreasing in the degree of product differentiation. That is, with $\gamma / \beta=0$, meaning independent goods, we have the maximum number of active firms, and with $\gamma / \beta=1$, meaning homogeneous goods, we have the minimum number of active firms. We can see the point where the differentiated Bertrand crosses over the homogeneous Cournot is at a high degree of product differentiation, thereby confirming our previous remark that for low values of $\gamma / \beta$ we expect $n_{B h}^{\star} \leq n_{C h}^{\star} \leq n_{B d}^{\star} \leq n_{C d}^{\star}$. Comparing the two figures, we see that with a nice linearly interpolated cost structure we get relatively smooth 
behavior of the number of active firm curves. However, with clustered costs, we can see that essentially each cluster is either wholly in or wholly out. This leads to the large flat regions of space with no change in structure, along with sudden large drops in the number of firms.

\section{Economic consequences of an equilibrium number of active firms}

The question to be answered is what determines the number of active firms in equilibrium in an oligopolistic market. That is, what factors can be used to give evidence for certain natural market concentrations. We posit that the type of competition, the degree of product differentiation and the cost structure in the market are the leading factors. The cost structure itself, although modeled quite simply here, can be thought of as incorporating more complicated cost scenarios into an effective marginal cost. For example, if entry to a market requires a high start-up cost, one can think of an additional firm that is not already in the market as having a high effective marginal cost when considering their entry/exit decision to the market.

\subsection{Type of competition}

We have studied Bertrand and Cournot type competition. Theorem 4.1 proves that the number of active firms in equilibrium is higher under Cournot type competition than Bertrand type. Therefore, one might naturally expect markets where price is the more natural strategic variable to be characterized by a more concentrated market. This leads to less product choice for the consumer. However, the increased level of competition that causes there to be less firms active also leads to lower average prices for the consumer. See Hackner [15] for this relationship between prices for substitute goods. Hence, in the Bertrand model, consumers are better off in terms of the prices they pay, but are worse off in terms of the variety of choices offered to them. On the other hand, in Cournot competition, consumers pay a premium for variety. The existence of more firms in equilibrium can be seen as desirable in terms of more choice, but there is an implicit cost for this benefit.

\subsection{Degree of Product Differentiation}

There are two extreme cases we can consider here: $\gamma / \beta=0$ and $\gamma / \beta=1$. In the former case, the goods are independent, and we will have the maximal number of active firms in the market. This means that maximal product differentiation is positive for the variety of options available to the consumer. But again, the dark side to variety is an increase in price. With $\gamma / \beta=0$, each firm acts as a monopoly, and consumers pay higher prices. Therefore, exactly as in the case of the type of competition, we see that more variety over the set of goods comes with the cost of higher prices. Moreover, the type of competition and the asymmetries in the cost structure are irrelevant to this result. Both Cournot and Bertrand result in the same number of active firms, and provided $s_{i}<\alpha$ for all $i$, the actual distribution of costs is inconsequential.

The other extreme is where goods are homogeneous. Here, we have the minimal number of active firms (depending on the mode of competition). This decrease in variety is somewhat offset by a decrease in the price paid by the consumer. Here the number of active firms does depend on the 
mode of competition. In the Bertrand case, we truly have the minimal number of active firms, only those with the lowest cost. In the Cournot case, we have more active firms, but this can still be significantly less than in a market with a lower $\gamma$-to- $\beta$ ratio. Therefore, we see that with a very high degree of product differentiation, meaning the goods are close to homogeneous, we expect to have a concentrated market, the more concentrated the market the closer the competition is to pure price competition. Additionally, homogeneous goods lead to lower prices, and the lowest possible prices in the case of Bertrand competition.

\subsection{Cost Structure}

The effect of cost asymmetries on the number of active firms is the least straightforward of the three factors. Clearly, all firms having equal cost leads to the greatest number of active firms, all else equal. Moreover, if the market has only one very low cost firm, with any number of high cost firms, we will have that the low cost firm serves the majority of demand and thus the market will be highly concentrated. Therefore, market concentration can be positive if it leads to the lowest cost producer meeting the majority of demand as this is the most efficient outcome. However, this cost asymmetry leads to a lack of variety for consumers. The low cost firm is capable of charging the lowest prices and producing the most output, however in many markets, there is likely only to be a small number of such firms. In industries where learning and greater intellectual property lead to drastic cost reductions, one is likely to observe markets that are highly concentrated with the lowest cost firms holding the largest market share. On the other hand, when a new entrant can achieve roughly the same marginal cost as an incumbent firm, one is likely to see much less market concentration in the form of more active firms. This feature can be seen as crucial throughout the models we have presented above because of the high dependence of the number of active firms on the sum of marginal costs of the lowest cost firms. In studies of oligopoly where costs are assumed equal across firms, such interesting and important features of real markets are overlooked.

\subsection{What is best for the consumer?}

This is of course a loaded question. It seems to be taken for granted that economic efficiency is one manner in which to judge what is best for the consumer. Moreover, greater competition is often seen to lead to greater levels of efficiency. See Vickers [28] for a discussion of how economic efficiency can be promoted by competition. In our analysis, the concept of competition is somewhat difficult to ascertain. On the one hand, a larger number of firms in the market could be seen to imply a more competitive market in the sense that each firm must compete with more varieties of goods for demand. This would lead one to the conclusion that Cournot competition is more competitive and can thus lead to greater economic efficiency. However, on the other hand, a market might have a small number of active firms, each of which is more efficient (in terms of cost) than those who are not active, because the competition is so great. Thus, the market might be more concentrated and consumers pay a lower price because of a large amount of competition. This leads one to the conclusion that Bertrand competition truly leads to greater economic efficiency.

However, economic efficiency is not the only way to judge what is best for a consumer. In fact, in this model, consumer surplus is the most accurate way to judge what is best for the consumer because it is denominated in units of utility. In our set-up, because of the results of Hsu and Wang [19], consumer surplus is higher in the Bertrand model than in the Cournot model. Thus, from a 
strictly utility point of view, a Bertrand market is better for the consumer. Intuitively, though, consumers want variety in their set of choices; see Lancaster [22] for a discussion of this issue. From this perspective, a Cournot market is better for the consumer. One way to address this might be to incorporate into the representative consumer's utility function some preference for having more choice.

This analysis has implications in the application of antitrust laws, in particular the use of the Herfindahl-Hirschman Index (HHI) by the Department of Justice in assessing the legality of a proposed merger. The above results translate to the statement that, ceteris paribus, Cournot markets have a lower HHI than Bertrand markets. However, in terms of competition, which this index is supposed to assess, one can strongly argue that Cournot markets are less competitive than Bertrand markets. Although this index is not meant to be comparable across different types of markets, the use of such an index relies on the assumption that market symmetry and more active firms are always better. However, the strength of competition in the Bertrand model results in a monopoly providing the lowest price because of the potential competition of higher cost firms. Therefore, this analysis is a clear indicator that the HHI is an incomplete metric. Similar results can be established for other common competition measurement indices.

There is a vast number of perspectives from which we can analyze such issues. For example, Geroski et al. [13] discuss other important areas of study that can lead to effects on consumer welfare such as imperfect information and collusion among firms. Our analysis leads to certain conclusions about what may be better for consumers. However, in the end, there is no clear answer that one market structure is preferred over another. The closest we can get to a concise conclusion is that cost symmetry is preferable to consumers. However, this comes with the caveat that symmetry is only good if those firms have low cost. Contrary to this perspective is that one would not want two equal and very high cost firms as opposed to one low cost and one high cost firm. With this caveat in mind, we find that less dispersion in the distribution of costs leads to many of the previous results being mitigated as the differences among firms decreases. But, this is not the case in practice. We find that cost asymmetries are vitally important to consider in the analysis of differential oligopoly games; see [16] and [23]. In those papers, as capacity or quantity of a resource of a firm diminishes over time, the effect is equivalent to a modification of the shadow cost of the firm. Hence, as firms interact dynamically over time, their effective local costs necessarily change and therefore even though one might hope for cost symmetry, it is highly unrealistic, especially under uncertainty of demand.

\section{Conclusion}

We have analyzed the number of firms who are active in equilibrium in Cournot type and Bertrand type oligopolies in the case of both homogeneous and differentiated goods. Moreover, we have considered crucially the case where firms have asymmetric costs. Our main finding is that for a given type of good structure (i.e. either homogeneous or differentiated) Cournot markets have more active firms than the corresponding Bertrand market. Further, the differentiated market has more active firms than the corresponding homogeneous market for both Cournot and Bertrand type oligopolies. We find that the degree of product differentiation is thus crucial for the determination of the natural market size. Our assumption of asymmetric costs was crucial as we have found that the results for equal costs across firms is very different than with asymmetric costs. Specifically, 
equal costs leads to the maximal number of active firms in a market, whereas asymmetric costs leads to the possibility that some firms are inactive in equilibrium. Our results do not say without certain stipulations that one mode of competition is more desirable for consumers than another. However, the essential result is that Bertrand markets give consumers less choices of goods, but they pay lower prices for those goods. On the other hand, Cournot markets give consumers an increased amount of variety, but at the cost of paying higher prices for those goods.

\section{References}

[1] R. Amir and J. Y. Jin. Cournot and Bertrand equilibria compared: substitutability, complementarity and concavity. Int. J. Ind. Organ., 19(3-4):303-317, 2001.

[2] R. Amir and V. Lambson. On the effects of entry in Cournot markets. Rev. Econ. Stud., 67:235-254, 2000.

[3] R. Amir and V. Lambson. Entry, exit, and imperfect competition in the long run. J. Econ. Theory, 110(1):191 - 203, 2003.

[4] J. Bertrand. Théorie mathématique de la richesse sociale. Journal des Savants, 67:499-508, 1883.

[5] R. Caldentey and M. Haugh. A Cournot-Stackelberg Model of Supply Contracts with Financial Hedging. Working paper, NYU Stern School of Business, 2010.

[6] R. Cellini, L. Lambertini, and G. Ottaviano. Welfare in a differentiated oligopoly with free entry: a cautionary note. Research in Economics, 58:125-133, 2004.

[7] A. Cournot. Recherches sur les Principes Mathématique de la Théorie des Richesses. Hachette, Paris, 1838. English translation by N.T. Bacon, published in Economic Classics, Macmillan, 1897, and reprinted in 1960 by Augustus M. Kelley.

[8] C. d'Aspremont, R. Dos Santos Ferreira, and L.-A. Gérard-Varet. Competition for market share or for market size: oligopolistic equilibria with varying competitive toughness. Int. Econ. Rev., 48(3), 2007.

[9] K. G. Dastidar. On the existence of pure strategy Bertrand equilibrium. Econ. Theory, 5:19-32, 1995.

[10] F. Edgeworth. Me teoria pura del monopolio. Giornale degli Economisti, 40:13-31, 1897. English translation: The pure theory of monopoly. In Papers Relating to Political Economy, Vol. I, edited by F. Edgeworth. London: Macmillan, 1925.

[11] W. Elberfeld and E. Wolfstetter. A dynamic model of Bertrand competition with entry. Int. J. Ind. Organ., 17(4):513 - 525, 1999.

[12] J. Friedman. Oligopoly Theory. Cambridge University Press, 1983.

[13] P. A. Geroski, L. Phlips, and A. Ulph. Oligopoly, competition and welfare: Some recent developments. J. Ind. Econ., 33(4):369-386, 1985.

[14] B. Golany and U. G. Rothblum. Optimal investment in development projects. Operations Research Letters, 36:657-661, 2008.

[15] J. Hackner. A note on price and quantity competition in differentiated oligopolies. J. Econ. Theory, 93 (2):233-239, August 2000.

[16] C. Harris, S. Howison, and R. Sircar. Games with exhaustible resources. SIAM J. Applied Mathematics, 70:2556-2581, 2010. 
[17] S. H. Hoernig. Bertrand games and sharing rules. Econ. Theory, 31:573-585, 2007.

[18] H. Hotelling. Stability in competition. Econ. J., 39(153):41-57, 1929.

[19] J. Hsu and X. Wang. On welfare under Cournot and Bertrand competition in differentiated oligopolies. Rev. Ind. Organ., 27:185-191, 2005.

[20] J. Jurgan. Cost variations in a differentiated good oligopoly. Working Papers 069, Bavarian Graduate Program in Economics (BGPE), February 2009.

[21] D. M. Kreps and J. A. Scheinkman. Quantity precommitment and Bertrand competition yield Cournot outcomes. Bell J. Econ., 14(2):326-337, 1983.

[22] K. Lancaster. The economics of product variety: A survey. Marketing Sci., 9(3):189-206, 1990.

[23] A. Ledvina and R. Sircar. Dynamic Bertrand oligopoly. Applied Mathematics and Optimization, 63: 11-44, 2011.

[24] A. Mas-Colell, M. D. Whinston, and J. R. Green. Microeconomic Theory. Oxford University Press, New York, New York, 1995.

[25] A. Mukherjee. Price and quantity competition under free entry. Research in Economics, 59:335-344, 2005.

[26] N. Singh and X. Vives. Price and quantity competition in a differentiated duopoly. RAND J. Econ., 15(4):546-554, 1984.

[27] G. Symeonidis. Comparing Cournot and Bertrand equilibria in a differentiated duopoly with product R\&D. Int. J. Ind. Organ., 21(1):39 - 55, 2003.

[28] J. Vickers. Concepts of competition. Oxford Econ. Pap., 47(1):1-23, 1995.

[29] X. Vives. Oligopoly pricing: old ideas and new tools. MIT Press, Cambridge, MA, 1999.

[30] P. Zanchettin. Differentiated duopoly with asymmetric costs. J. Econ. Manage. Strategy, 15:999-1015, 2006. 